\title{
Color Based Recognition and Estimation of Temperature Levels of Images of Boiled Food Grains
}

\author{
Basavaraj S. Anami \\ Principal, K.L.E. Institute of Technology, \\ Hubli-580030, India
}

\author{
Vishwanath C. Burkpalli \\ Research Scholar, Basaveshwar Engineering College, \\ Bagalkot - 587102, India
}

\begin{abstract}
Automated food processing and evaluation is considered a significant research area in computer vision. The development of automated cooking and food serving by robots is envisaged as part of automated food processing and temperature plays a major role in cooking Indian foods. The delicious Indian foods are generally boiled or fried with other ingredients. The boiled grains like Bengal Gram, Black Gram, Green Gram, Red Gram and Toor Dal are part of typical Indian foods and taste differently, when boiled or cooked at different temperatures and periods of time. Therefore, identifying the effect of boiling and automatic recognition of images of boiled food grains is presented in this paper. The boiling temperatures chosen are $40^{\circ} \mathrm{C}, 50^{\circ} \mathrm{C}, 60^{\circ} \mathrm{C}$, $80^{\circ} \mathrm{C}$ and $100^{\circ} \mathrm{C}$. A color feature centered knowledge based classifier is proposed. The classification accuracy observed is high at lower and higher temperatures and low at medium temperatures. The work finds applications in automatic inspection of food preparations in food industries, drug preparation in pharmaceutical industries, automatic serving, cooking and monitoring of foods in restaurants and motels.
\end{abstract}

\section{Keywords}

Color Features, Knowledge Based Classifier, Boiled Food Grains.

\section{INTRODUCTION}

The food industries involve many activities, such as inspection of food preparations, food quality evaluation, monitoring the processes, etc and are being performed manually. These activities are considered tedious, laborious and cost intensive. However, the activities are inherently unreliable due to its subjective nature; increased demands for objectivity, consistency and efficiency of human beings. This necessitates automation of the activities in the food and pharmaceutical industry through development of computer vision systems. One of the activities considered is recognition of images of boiled food grains.

Boiling and frying are common in Indian food preparations. Sometimes, the food grains are boiled at different temperatures in food preparations and the level of boiling is determined by visual inspection. Human experts take decision as to how long the food grains should be boiled, how food looks etc during the process. To overcome the problem of human experts and also their inherent limitations, the machine vision systems are being developed. We propose in this paper a methodology for recognition of boiled food grains and different boiling temperatures. Color and texture change with grain types and also with the temperatures. Hence, different color features are extracted from the images and a knowledge based classifier is developed for classification of different food grains like Red Gram, Green Gram etc.
The literature survey reveals certain connected works being carried in the area of computer applications in food processing. (Lin D et.al, 2007) have proposed an image color intensity analyzer for images in order to obtain different intensities of color components in both the RGB and hue-saturation-intensity (HSI) color spaces. It is shown that hue and saturation correlate very well with temperatures, which implies that the HSI color space is suitable for the study of the behavior of fire-damaged concrete. (M.M. Lana et.al, 2006) have proposed the development of translucency and its interference with color measurement in freshcut tomatoes. The effects of stages of maturity at the time of processing as well as the effect of storage temperature are studied in two separate experiments. A model is developed that describes the change in the RGB values of tomatoes after cutting and during storage. It is inferred that the observed effects are the result of two processes namely, changes in color due to the production or degradation of pigments and development of translucency (i.e. physical water-soaking).

(M.M. Lana et.al 2006) have developed a model to assess changes in optical properties of fresh-cut tomato using video image analysis. Tomato fruit (Lycopersicon esculentum cv. Belissimo) at different stages of maturity are sliced in 7-mm thick transverse slices and stored at $5{ }^{\circ} \mathrm{C}$. In another experiment, slices obtained from fruit at the light-red stage are stored at temperatures from 5 to $13{ }^{\circ} \mathrm{C}$. The development of translucency in the pericarp is the main change in appearance of cut tomato. This process is affected by the stage of maturity of the fruit and independent of storage temperature. (Zhao-yan Liu et.al, 2005) have described image analysis algorithm based on color and morphological features for identifying different varieties of rice seeds. Seven color features and fourteen morphological features are used for discriminate analysis. A two-layer neural network model is developed for classification.

(L.Fernandez et. al 2004) have presented a method based on computer vision to analyze the effect of drying on shrinkage, color and image texture of apple discs. Texture feature using cooccurrence matrix and $\mathrm{L}^{*} \mathrm{a}^{*} \mathrm{~b}^{*}$ color feature are used. A Euclidian distance classifier is used for classifying different stages of apple discs and 95\% classification accuracy is reported.

(F. Pedrerschi P. et.al, 2004) have developed an approach to classify potato chips using pattern recognition from color digital images. Eleven features are selected according to their classification attributes. Classification of the 6 classes is in the confidence interval of $78 \%$ and $89 \%$ with a probability of $95 \%$ is observed. (Anami B.S et.al, 2003) have developed a method for classification and gradation of different grains such as Ground nut, Bengal Gram, wheat etc. Geometrical and color features such as Size, Shape, Red, Green, Blue etc., are extracted and a neural network model is proposed for classification. 
(Majumdar S. et.al, 1999) have proposed a method to identify and classify bulk cereal food grains using artificial neural network. (A. Beatty et.al, 1993 have presented ongoing research in knowledge based vision, which addresses the problem of quality grading within the fish processing industry. (Gary Kay et.al, 1992) have proposed a color system for high speed color classification of fruits in automatic fruit sorting environment.

From the published research work, it is observed that color and texture features are being widely used. Work connected with food grains and temperature is not much observed. This is the motivation for taking up a work on effect of temperature in identification and classification of boiled food grains.

The images of boiled food grains at different temperatures are considered. The levels of boiling are dependent on grain types and also vary with perception of individuals. The images of the boiled food grains namely, Bengal Gram (Cicer arietinum), Tur Dal (Fragaria), Green Gram (Vigna radiate), Black Gram (Vigna mungo) and Red Gram also called Musurki Dal (Caroluslinnaeus) are considered for recognition and classification. The HSV color features are extracted from these boiled grain images. A knowledge based classifier is developed and tested for recognition accuracies of different boiled grains.

The paper is organized into five different sections. Section 2 contains the proposed methodology. Section 3 presents a description of Knowledge based classifier. The results and discussion are given in section 4. The paper is concluded with section 5 .

\section{PROPOSED METHODOLOGY}

The proposed methodology consists of four stages, namely, image acquisition, feature extraction, knowledge base creation and a classifier. The block diagram of the proposed methodology is shown in Figure 1.

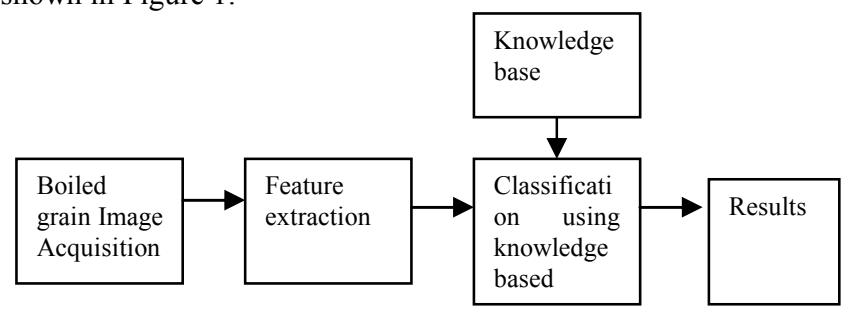

Figure 1: Block Diagram of Proposed Methodology

\subsection{Image Acquisition}

The food grains are boiled in a Microwave oven Samsung model CE1031LAT. The power level function of the oven enables us to set the temperature levels at $40^{\circ} \mathrm{C}(180 \mathrm{w}), 50^{\circ} \mathrm{C}(300 \mathrm{w}), 60^{\circ} \mathrm{C}$ $(450 \mathrm{w}), 80^{\circ} \mathrm{C}(600 \mathrm{w})$ and $100^{\circ} \mathrm{C}(900 \mathrm{w})$. We have taken 100 grams of each type of grains, mixed with $200 \mathrm{ml}$ of filtered water having the $\mathrm{pH}$ value of 7 and TDS (Total Dissolving Solution) value of 105 and boiled. The boiling time of food grains varies with grain types. We have set the boiling times on trial basis and are 30, 15, 15, 10 and 25 minutes for Bengal Gram, Black Gram, Green Gram, Red Gram and Toor Dal respectively.

A Sony Alpha digital color camera with an image resolution of 10 mega pixels is used for capturing images of boiled food grains. The camera is vertically oriented and fixed at a distance of $0.5 \mathrm{~m}$ from the surface of the boiled food.

\subsection{Feature Extraction}

There are various color models used for image classification. The RGB model is commonly used in hardware oriented applications. When viewing a color object, human visual system characterizes it by its brightness and chromaticity. The latter is defined by hue and saturation. Brightness is a subjective measure of luminous intensity. It embodies the achromatic notion of intensity. Hue is a color attribute and represents a dominant color. Saturation is an expression of the relative purity or the degree to which a pure color is diluted by white light. The HSV model is motivated by the human visual system. In the HSV model, the luminous component (brightness) is decoupled from color-carrying information (hue and saturation). Hence, in our experiment we used HSV color model.

The grains have certain color and retain the same even after boiling. We have used color features based on H S V Model. The Red, Green and Blue components are separated from the original image. The Hue $(\mathrm{H})$, Saturation $(\mathrm{S})$ and Value $(\mathrm{V})$ components are extracted from these RGB components. The equations (1), (2) and (3) are used to obtain Hue, Saturation and Value respectively for a given image sample.

$H=\cos ^{-1}\left\{\frac{\frac{1}{2}[(R-G)+(R-B)]}{\sqrt{(R-G)^{2}+(R-B)(G-B)}}\right\}$

$S=1-\frac{3}{R+G+B}[\min (R, G, B)]$

$V=\frac{1}{3}(R+G+B)$ $-(2)$

Figure 2 shows digital images of $40^{\circ} \mathrm{C}, 50^{\circ} \mathrm{C}, 60^{\circ} \mathrm{C}, 80^{\circ} \mathrm{C}$ and $100^{\circ} \mathrm{C}$ temperature boiled samples of food grains and Figure 3 shows their corresponding color feature histograms. Abbreviations used are (BLKG) Black Gram; (BNGG) Bengal gram; (GG) Green Gram; (TD) Toor Dal; (Min) minimum value; (Max) maximum value; (RG) Red Gram; (H) Hue Component, (S) Saturation Component; (V) Value Component.

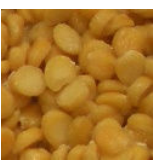

(i)

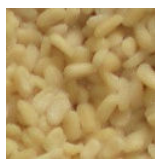

(ii)

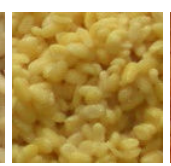

(iii)

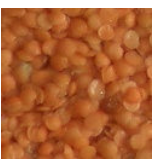

(iv)

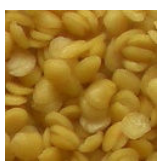

(v) (a) At Temperature $40^{\circ}$ Celsius

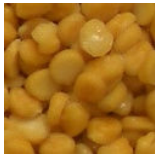

(i)

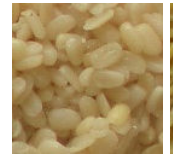

(ii)

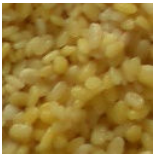

(iii)

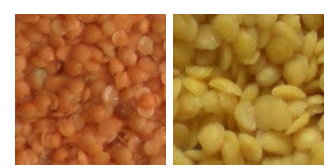

(iv) (v) (b) At Temperature $50^{\circ}$ Celsius 


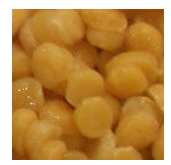

(i)

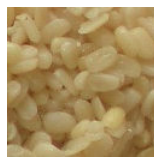

(ii)

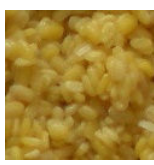

(iii)

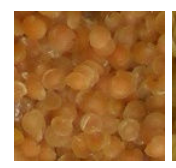

(iv)

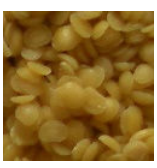

( (c) At Temperature $60^{\circ}$ Celsiu' $^{\circ}$

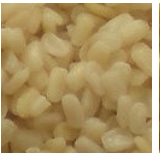

(i)

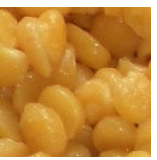

(i)

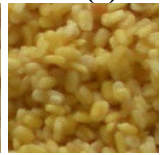

(ii)

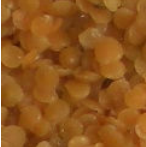

(iii)

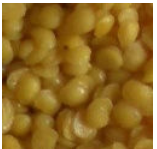

(iv) (v)

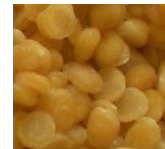

(d) At Temperature $80^{\circ}$ Celsius

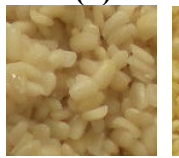

(ii)

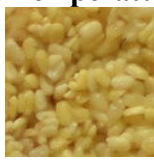

(iii)

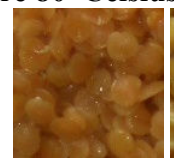

(iv)

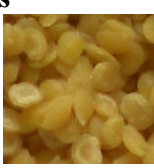

(v)

(e) At Temperature $100^{\circ}$ Celsius

Figure 2: Boiled Food Grain Image Samples. (i) Bengal Gram (ii) Black Gram (iii) Green Gram (iv) Red Gram (v) Toor Dal

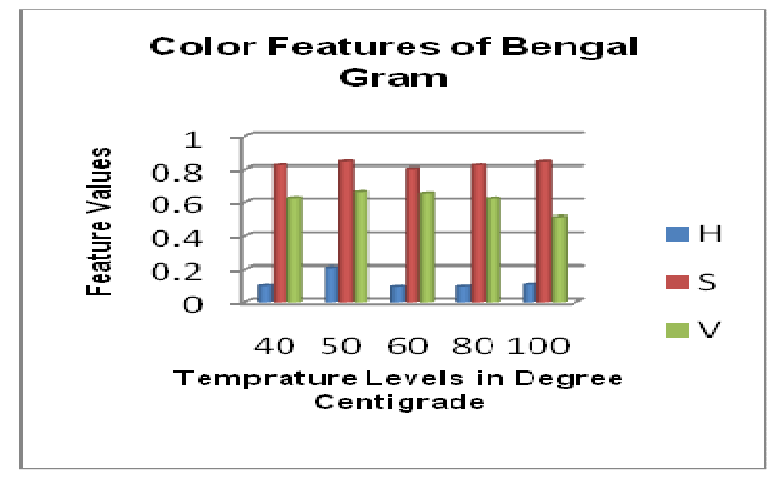

(a)

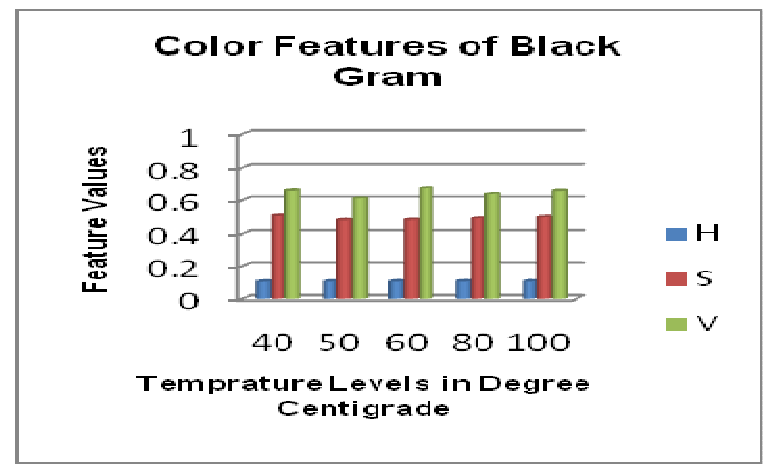

(b)

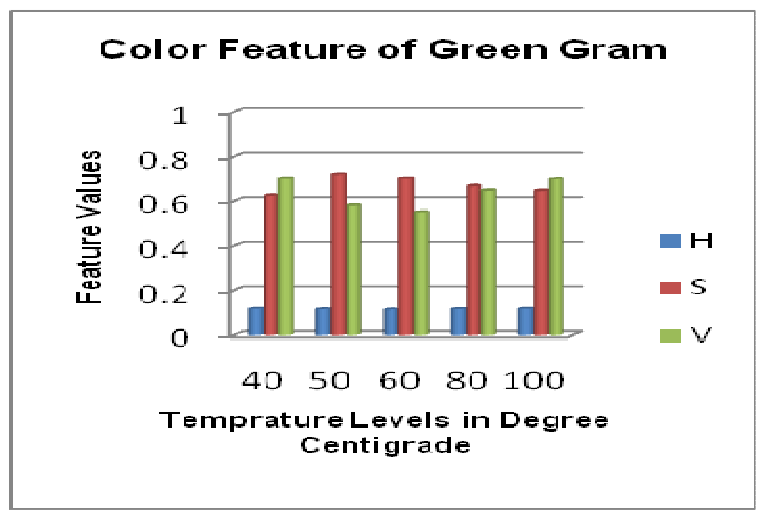

(c)

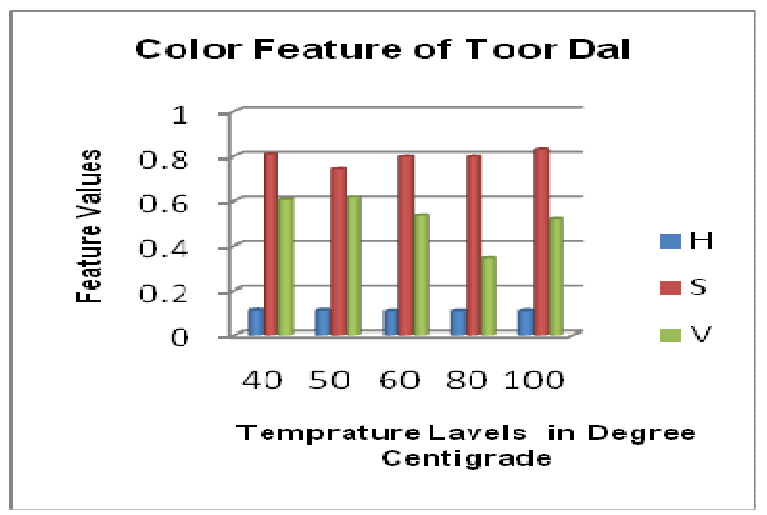

(d)

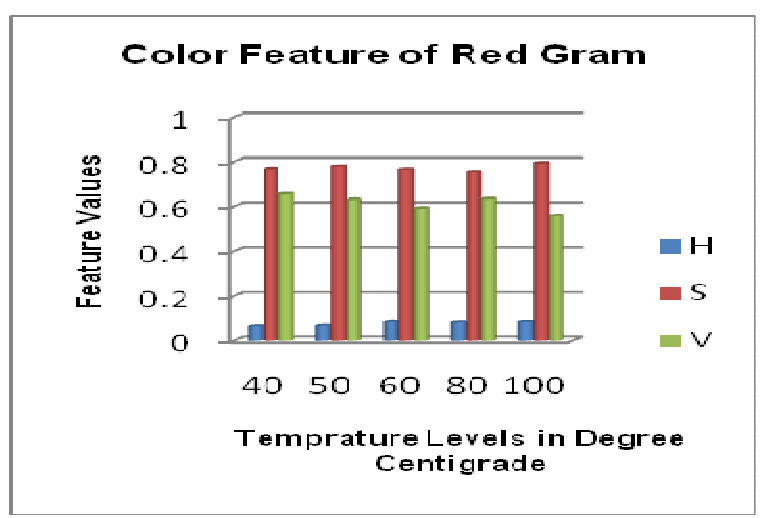

(e)

Figure 3: Color Feature Values of Boiled Food Grains. (a) Bengal Gram (b) Black Gram (c) Green Gram (d) Red Gram (e) Toor Dal

Amongst HSV values, we have observed that Hue is not predominant compared to saturation and value. Thus, only $\mathrm{S}$ and $\mathrm{V}$ participation in the recognition process is considered

\subsection{Knowledge Base}

A frame structure is used for knowledge representation, which consists of slots and slot values. The slots typically have names and values called facets. Typically a slot contains information about the color features $(\mathrm{H}, \mathrm{S}$, and $\mathrm{V})$ and their minimum and maximum values. The features extracted from the images are 
stored in frames and the collection of such frames forms a knowledge base. The knowledge base used for boiled grain classification shown in Table 1. The knowledge base used for classification based on temperature using saturation (S) only is shown in Table 2. A typical frame is given as under Figure 4. In the experiment, the large numbers of samples are tested to obtain the minimum and the maximum feature values for a given image of size $300 \times 300$ as depicted in Table 1 and Table 2 . In case, the value changes with acquisition devices or image resolution, the knowledge base needs to be changed accordingly.

\section{Color-frame (Bengal Gram) [}

(H (MIN-Value (0.099))

(MAX-Value (0.99)))

(S (MIN Value (0.804))

(MAX Value (0.865)))

(V (MIN Value (0.478))

(MAX Value (0.685)))

Figure 4: Frame Structure for Color for Bengal Gram Table 1: Knowledge Base used for Classification of Types of

\begin{tabular}{|c|c|c|c|c|c|c|}
\hline $\begin{array}{c}\text { Type of } \\
\text { Boiled } \\
\text { Grain }\end{array}$ & \multicolumn{2}{|c|}{ Hue } & \multicolumn{2}{c|}{ Saturation } & \multicolumn{2}{c|}{ Value } \\
\hline $\begin{array}{c}\text { Bengal } \\
\text { Gram }\end{array}$ & 0.099 & 0.99 & 0.804 & 0.865 & 0.478 & 0.685 \\
\hline $\begin{array}{c}\text { Black } \\
\text { Gram }\end{array}$ & 0.108 & 0.117 & 0.466 & 0.507 & 0.439 & 0.689 \\
\hline $\begin{array}{c}\text { Green } \\
\text { Gram }\end{array}$ & 0.114 & 0.122 & 0.611 & 0.738 & 0.537 & 0.733 \\
\hline $\begin{array}{c}\text { Red } \\
\text { Gram }\end{array}$ & 0.061 & 0.084 & 0.725 & 0.829 & 0.494 & 0.709 \\
\hline $\begin{array}{c}\text { Toor Dal } \\
\text { MAX }\end{array}$ & 0.105 & 0.113 & 0.733 & 0.837 & 0.505 & 0.651 \\
\hline
\end{tabular}

Table 2: Knowledge Base for Classification Based on Temperature using $S$ value

\begin{tabular}{|l|l|l|l|l|l|l|}
\hline $\begin{array}{c}\text { Type } \\
\text { of } \\
\text { Boiled } \\
\text { Grain }\end{array}$ & & $\mathbf{4 0}^{\mathbf{0}} \mathbf{C}$ & $\mathbf{5 0}^{\mathbf{0}} \mathbf{C}$ & $\mathbf{6 0}^{\mathbf{0}} \mathbf{C}$ & $\mathbf{8 0}^{\mathbf{0}} \mathbf{C}$ & $\mathbf{1 0 0}^{\mathbf{0}} \mathbf{C}$ \\
\hline \multirow{2}{*}{$\begin{array}{l}\text { Bengal } \\
\text { Gram }\end{array}$} & MIN & 0.792 & 0.838 & 0.792 & 0.814 & 0.837 \\
\cline { 2 - 7 } Black & MIN & 0.846 & 0.865 & 0.824 & 0.833 & 0.860 \\
\cline { 2 - 7 } Gram & MAX & 0.569 & 0.484 & 0.495 & 0.5 & 0.507 \\
\hline \multirow{2}{*}{$\begin{array}{l}\text { Green } \\
\text { Gram }\end{array}$} & MIN & 0.611 & 0.705 & 0.674 & 0.639 & 0.628 \\
\cline { 2 - 7 } Red & 0.643 & 0.738 & 0.713 & 0.682 & 0.665 \\
\cline { 2 - 7 } Gram & MAX & 0.758 & 0.764 & 0.759 & 0.715 & 0.782 \\
\hline \multirow{2}{*}{$\begin{array}{l}\text { Toor } \\
\text { Dal }\end{array}$} & MIN & 0.795 & 0.721 & 0.774 & 0.814 & 0.775 \\
\cline { 2 - 7 } & MAX & 0.835 & 0.753 & 0.809 & 0.844 & 0.790 \\
\hline
\end{tabular}

\section{KNOWLEDGE BASED CLASSIFIER}

A knowledge based classifier is designed, which comprises of a set of rules constituting an inference engine, used for the classification of boiled food grains. The sequence of rules is fired depending on the feature values to give the types of grain samples and their boiling levels. The inference process is divided into two levels namely, first level and second level. In the first level classification grain type is carried out. The process adopted in the first level is given in Algorithm1. In the second level the boiling levels are determined. The process adopted in the second level is given in Algorithm2.

\section{Algorithm1: First Level Classification}

Input: Values of h, s and $v$ features.

Output: Grain type

Start:

Step1: if ((hBNGGMin $<=\mathrm{h}<=\mathrm{hBNGGMax}) \&$

(sBNGGMin $<=$ s $<=$ s BNGGMax) \&

(vBNGGMin $<=$ v $<=$ vBNGGMax))

then

$$
\text { grain_type }=\text { Bengal Gram }
$$

Step2: if $((\mathrm{hTDMin}<=\mathrm{h}<=\mathrm{hTDMax}) \&$

$$
\begin{aligned}
& (\text { sTDMin }<=\mathrm{s}<=\text { sTDMax }) \& \\
& (\text { vTDMin }<=\mathrm{v}<=\text { vTDMax })
\end{aligned}
$$

then

$$
\text { grain_type }=\text { Toor Dal }
$$

Step3: if ((hGGMin $<=\mathrm{h}<=\mathrm{hGGMax}) \&$

$$
\begin{gathered}
(\mathrm{sGGMin}<=\mathrm{s}<=\text { sGGMax }) \& \\
(\text { vGGMin }<=\text { v }<=\text { vGGMax })
\end{gathered}
$$

then

grain_type $=$ Green Gram

Step4: if ((hBLKGMin $<=\mathrm{h}<=\mathrm{hBLKGMax}) \&$ ( $\operatorname{sBLKGMin}<=\mathrm{s}<=$ sBLKGMax) \& $($ vBLKGMin $<=$ v $<=$ vBLKGMax $)$ )

then

grain_type = Black Gram

Step5: if ((hRGMin $<=\mathrm{h}<=\mathrm{hRGMax}) \&$ ( $\operatorname{sRMin}<=$ s $<=$ sRGMax) \& (vRGMin $<=$ v $<=$ vRGMax))

then

grain_type $=$ Red Gram

Step 6: Call second_level_classification (grain_type, s) /*Algorithm 2*/ 


\section{Stop}

\section{Algorithm2: Second Level Classification}

Input: Value of $\mathrm{s}$.

Output: Temperature levels $40^{\circ} \mathrm{C}, 50^{\circ} \mathrm{C}, 60^{\circ} \mathrm{C}, 80^{\circ} \mathrm{C}$ and $100^{\circ}$

C.

Start:

Step1: if $\left(\left(\mathrm{s} 40^{\circ} \mathrm{C} \operatorname{Min}<=\mathrm{s}<=\mathrm{s} 40^{\circ} \mathrm{C}\right.\right.$ Max $)$

then

Display 'Boiled Bengal Gram around $40^{\circ} \mathrm{C}$ ' and stop

Step2: if $\left(\left(\mathrm{s} 50^{\circ} \mathrm{C}\right.\right.$ Min $<=\mathrm{S}<=\mathrm{s} 50^{\circ} \mathrm{C}$ Max $)$

then

Display 'Boiled Bengal Gram around $50^{\circ} \mathrm{C}$ ' and stop

Step3: if $\left(\left(\mathrm{s} 60^{\circ} \mathrm{C}\right.\right.$ Min $<=\mathrm{s}<=s 60^{\circ} \mathrm{C}$ Max $)$

then

Display 'Boiled Bengal Gram around $60^{\circ} \mathrm{C}$ ' and stop

Step4: if $\left(\left(\mathrm{s} 80^{\circ} \mathrm{C}\right.\right.$ Min $<=\mathrm{s}<=\mathrm{s} 80^{\circ} \mathrm{C}$ Max $)$

then

Display 'Boiled Bengal Gram around $80^{\circ} \mathrm{C}$ ' and stop

Step5: if $\left(\left(\mathrm{s} 100^{\circ} \mathrm{C} \operatorname{Min}<=\mathrm{s}<=\mathrm{s} 100^{\circ} \mathrm{C}\right.\right.$ Max $)$

then

Display 'Boiled Bengal Gram around $100^{\circ} \mathrm{C}$ ' and stop

\section{RESULTS AND DISCUSSION}

This section gives the results of experiments carried out on the developed knowledge based classifier. We have considered 2500 image samples by drawing 100 images at each stage for each food grain type. It is observed that the saturation(S) feature yields higher accuracy compared to hue $(\mathrm{H})$ and value $(\mathrm{V})$ features of HSV model. Hence, we have tested the classifier with only saturation feature (S). The classification accuracy is higher at temperatures in the range $40^{\circ}-50^{\circ}$ and $80^{\circ}-100^{\circ} \mathrm{C}$. But it is low at temperatures around $60^{\circ} \mathrm{C}$. This is because at this temperature level, the food grains are not completely boiled and the color changes are not predominant. This has resulted in maximum overlap in the feature values. It is evident to human vision system also in this range and hence reduction in classification efficiency is observed. We have used the formula (4) to estimate the classification accuracy.

$$
\text { Accuracy }=\frac{\text { Correctly } \operatorname{Re} \text { cognized Samples }}{\text { Total no of test samples }} \times 100 \text {.. }
$$

The histograms of classification accuracies are plotted as shown in Figure 5, Figure 6 Figure 7, Figure 8 and Figure 9 for $40^{\circ} \mathrm{C}, 50^{\circ}$ $\mathrm{C}, 60^{\circ} \mathrm{C}, 80^{\circ} \mathrm{C}$ and $100^{\circ} \mathrm{C}$ respectively. It is observed that the average classification accuracy is nearly the same in all the cases. Hence, the efficiency of the classifier is considered consistent.
The average classification accuracies with feature values of $\mathrm{V}, \mathrm{S}$ and $\mathrm{HSV}$ are $36 \%, 57 \%$ and $50 \%$ respectively. Hence, results show that classification using $\mathrm{S}$ value is better than with $\mathrm{V}$ and HSV value.

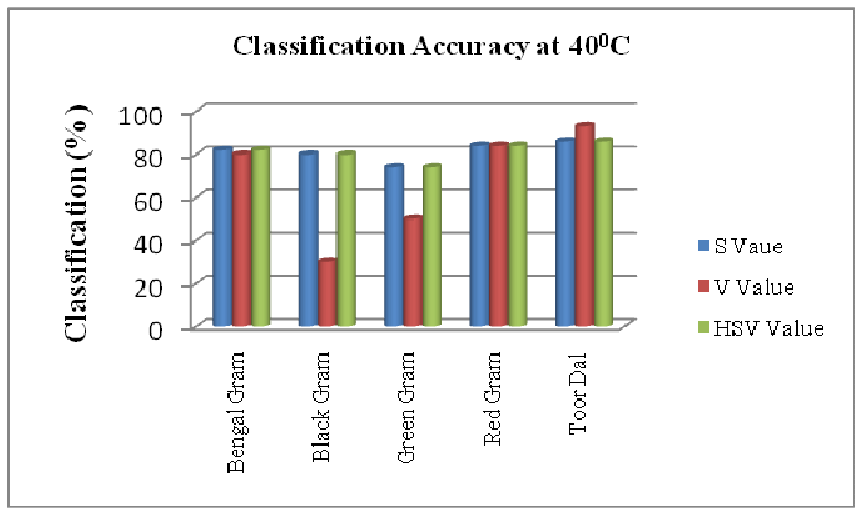

Figure 5: Classification Accuracy at $40^{\circ} \mathrm{C}$

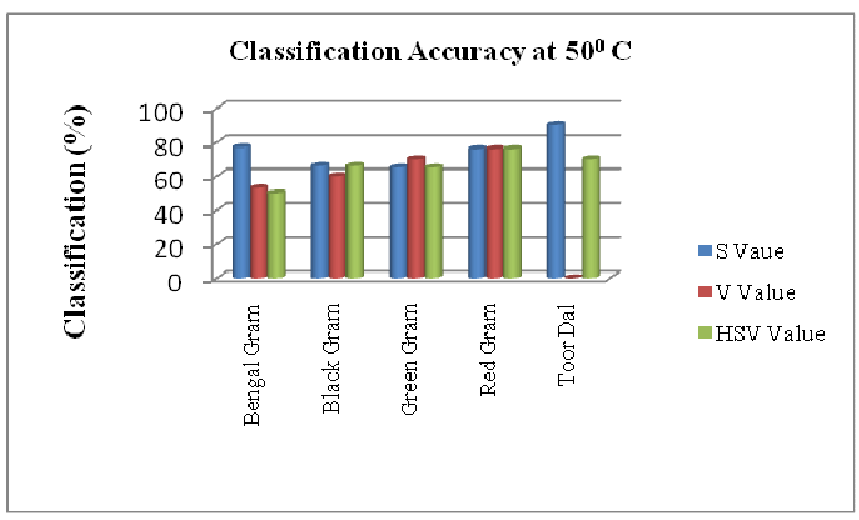

Figure 6: Classification Accuracy at $50^{\circ} \mathrm{C}$

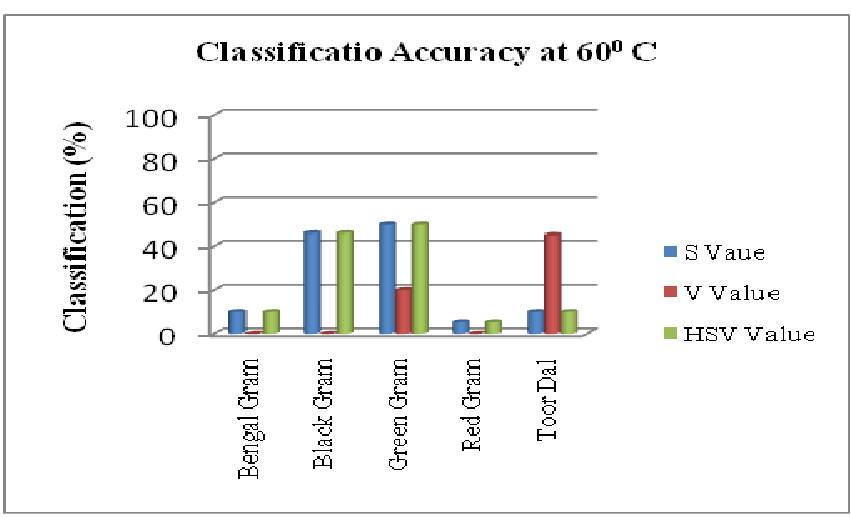

Figure 7: Classification Accuracy at $60^{\circ} \mathrm{C}$ 


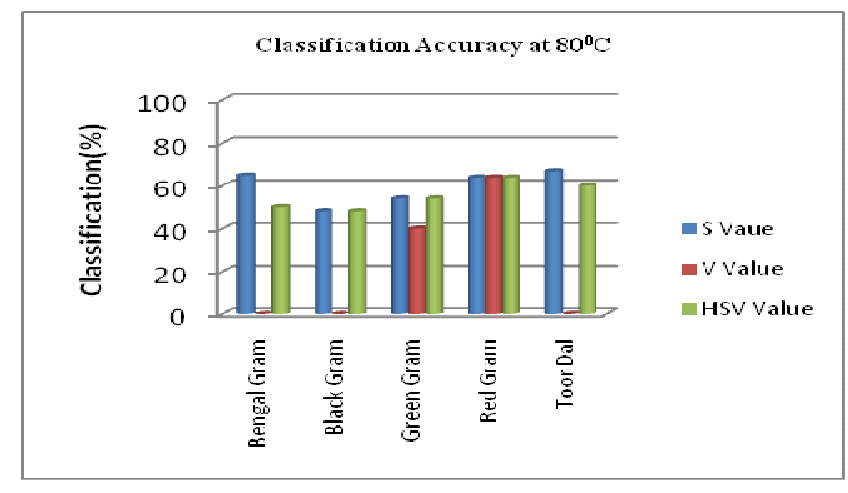

Figure 8: Classification Accuracy at $80^{\circ} \mathrm{C}$

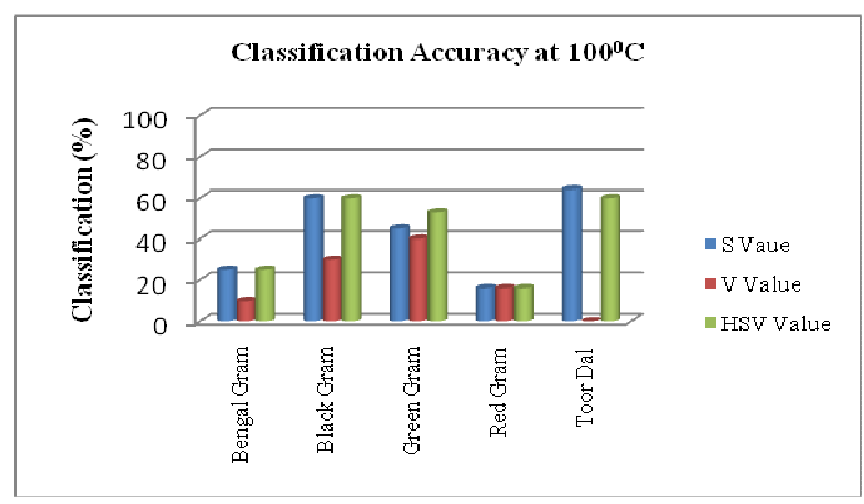

Figure 9: Classification Accuracy at $100^{\circ} \mathrm{C}$

\section{CONCLUSION}

This paper proposes a methodology based on color feature, for finding the effect of temperature on identification of boiled food grains. RGB model is used. The knowledge based classifier has given good average accuracy. Results show that the classification accuracy is higher at lower and higher temperatures. But, at medium temperature (i.e., $60^{\circ} \mathrm{C}$ ), the accuracy is low because of change in color feature values is less. There is scope for improving the accuracy at medium temperatures. The work finds applications in automatic inspection of food preparations in food industry, restaurants, motels, pharmaceutical industry and the like.

\section{REFERENCES}

[1] Anami B S and D G Savakar, (2009). Improved method for Identification of Foreign Bodies Mixed Food Grain Image Samples, International Journal of Artificial Intelligence and machine learning(AIML), Vol 9, Issue 1, pp 1-9.

[2] B.S.Anami, Vishwanath Burkpalli, S. A. Angadi, Nagamma Patil, (2003). Neural network approach for grain classification and gradation, Proceedings of the second national conference on document analysis and recognition, pp 394-405.

[3] B.S.Anami,Vishwanath Burkpalli, Sharanabasappa Madival, (2005). A texture based approach for classification of bulk boiled food grain images, Proceedings of the International conference on Cognation and Recognition, pp 419-426.

[4] A. Beatty, R.G. Gosine, \& C.W. de Silva, (1993). Recent Developments In The Application Of Computer Vision For Automated Herring Roe Assessment, in the proceedings of IEEE Pacific Rim Conference on Communications Computers and Signal Processing, pp 698-701.

[5] Bin Zhu, Lu Jiang, Yaguang Luo \& Yang Tao, (2007). Gabor feature-based apple quality inspection using kernel principal component analysis. Journal of Food Engineering. Vol. 81, Issue 4, pp 741-749.

[6] Lin D, Luo H, Lee J, (2007). Effects of Temperatures on Mortar Quantified by Surface Color Changes, Journal of ASTM International (JAI), Vol 4, Issue 4.

[7] Chen. Y-R, (1989). Applying Knowledge Based expert System to meat grading, IEEE Conference Proceedings of the AI Systems in Government Conference of the Annual, pp-120-123.

[8] Cheng-Jin Du, Da-Wen, (2005). Pizza sauce spread classification using color vision and support vector machines. Journal of Food Engineering. Vol. 66, Issue 2, 2005, Page 137-145.

[9] Gary Kay, Gerhard de Jager. (1992). A Versatile Color System Capable of Fruit Sorting and Accurate Object Classification, proceedings of the 1992 South African Symposium COMSIG, pp 145-148.

[10] F.Pedrerschi. Mery, F.Mendoza \& J.M. Aguilera, (2004). Classification of Potato Chips Using Pattern Recognition, Journal of Food Science. Vol. 69, pp-E264-270.

[11] Liyanage C De Silva, Anton Pereira, \& Amal Punchihewa, (2005). Food Classifications using Color Imaging, Conference on Image and Vision Computing New Zealand (ivenz) University of Otago, Dunedin, pp 1-6.

[12] Majumdar, S. D.S.Jayas, (1999). Classification of bulk Objects of Cereal grains using machine vision system, Journal of Agricultural Engineering Research. Vol. 731(1), pp. 35-37.

[13] M.M. Lana, L.M.M. Tijskens, O. van Kooten, (2006). Modeling $R G B$ color aspects and translucency of fresh-cut tomatoes, Postharvest Biology and Technology, Volume40,Issue1,April2006,Pages15-25

[14] M.M. Lana, L.M.M. Tijskens, A. de Theije, M. Hogenkamp, O. van Kooten, (2006). Assessment of changes in optical properties of fresh-cut tomato using video image analysis, Postharvest Biology and Technology, Volume 41, Issue 3, Pages,296-306.

[15] Zhao-yan Liu, Fang Cheng, Yi-bin Ying, \& Xiu-qin Rao, (2005). Identification of rice seed varieties using neural network. Journal of Zhejiang University SCIENCE B, Vol. 6(11), pp 1095-1100. 